Valck, C. de, Bensing, J., Bruynooghe, R.

Medical students' attitudes towards breaking bad news: an empirical test of

the World Health Organization model.

Psycho-Oncology: 10, 2001, p. 398-409

\begin{tabular}{|l|l|}
\hline Postprint Version & 1.0 \\
\hline Journal website & $\underline{\text { http://dx.doi.org }}$ \\
\hline Pubmed link & $\begin{array}{l}\text { http://www.ncbi.nlm.nih.gov/entrez/query.fcgi? cmd=Retrieve\&db=pubmed\&dop } \\
\mathrm{t}=\text { Abstract\&list uids=11536418\&query_hl=45\&itool=pubmed_docsum }\end{array}$ \\
\hline DOI & $10.1002 /$ pon.520
\end{tabular}

\title{
MEDICAL STUDENTS' ATTITUDES TOWARDS BREAKING BAD NEWS: AN EMPIRICAL TEST OF THE WORLD HEALTH ORGANIZATION MODEL
}

\author{
C. DE VALCK ${ }^{\mathrm{A}, *}$, J. BENSING ${ }^{\mathrm{B}}$ AND R. BRUYNOOGHE ${ }^{\mathrm{B}}$ \\ ${ }^{\text {a} H e a l t h ~ P s y c h o l o g y ~ D e p a r t m e n t, ~ F a c u l t y ~ o f ~ M e d i c i n e, ~ L i m b u r g s ~ U n i v e r s i t y ~ C e n t r e, ~ D i e p e n b e e k, ~}$ \\ Belgium \\ ${ }^{\mathrm{b}}$ Netherlands Institute for Primary Health Care, Utrecht, Netherlands \\ *Correspondence to: Health Psychology Department, Faculty of Medicine, Limburgs University Centre, \\ 3590 Diepenbeek, Belgium. Tel.: +32 11 268697; fax: 003211 268700; e-mail: \\ chris.devalck@luc.ac.be
}

\begin{abstract}
SUMMARY
The literature regarding breaking bad news distinguishes three disclosure models: nondisclosure, full-disclosure and individualized disclosure. In this study, we investigated the relations between attitudes regarding disclosure of bad news and global professional attitudes regarding medical care in a sample of medical students $(n=88)$. The Attitudes towards Breaking Bad News Questionnaire was developed and factor analysed to provide a valid and reliable instrument to measure attitudes regarding disclosure of bad news. The results indicate a preference for an individualized, patient-centred disclosure model in male and female students. Regarding the global professional attitudes, female students appear more humane-oriented than male students. Second, the relationship between global professional attitudes and attitudes regarding breaking bad news was examined by means of correlational and cluster analysis. The inter-relationship between global professional attitudes and attitudes regarding bad news is poor. Results of the cluster analysis, however, suggest that the sample can be divided into subsamples representing different disclosure clusters on the basis of specific combinations of global professional attitudes regarding medical care and attitudes regarding breaking bad news. The results are discussed in view of the theoretical framework proposed by the World Health Organization (WHO) in their training module on communication of bad news.
\end{abstract}

\section{INTRODUCTION}

Despite the growing interest in the literature on breaking bad news (Buckman, 1988; Fallowfield et al., 1995; Maguire et al., 1996), it remains unclear how the disclosure of bad news is influenced by physician's attitudes. Several questionnaire- based studies (Mystakidou et al., 1996; Rodriguez-Marin et al., 1996; Burton and Parker, 1997) have examined attitudes of medical students and physicians regarding bad news in different cultural and professional settings. These studies show that attitudes concerning disclosure of bad news are variable and determined by various factors, including patient's demographic variables, patient's anticipated reaction, cultural background, prognosis of the disease, doctor's ethical principles, doctor's speciality, doctor's status and clinical experience. Apart from the problem that the data of these studies are incomparable owing to different methods of assessment of 
Valck, C. de, Bensing, J., Bruynooghe, R.

Medical students' attitudes towards breaking bad news: an empirical test of

the World Health Organization model.

Psycho-Oncology: 10, 2001, p. 398-409

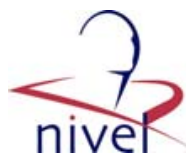

attitudes, the major problem, however, with these empirical studies is that they are not theory-driven, so that it remains unclear what the theoretical components are that make physicians prefer one or another communication model.

In this paper, we want to present empirical data of attitudes towards breaking bad news that are based on different theoretical frameworks. These are deduced from a comprehensive model proposed by the World Health Organization (WHO) in its behavioural science learning model on communicating bad news (Donovan, 1993). Within this framework, Donovan distinguishes a non-disclosure, a fulldisclosure, and an individualized disclosure model. According to Donovan, these three disclosure models are related to more global professional attitudes regarding the doctor-patient relationship, management decision-making style and overall doctor-patient communication (Table 1).

\section{[ TABLE 1 ]}

The theoretical base for this model is found in the literature on overall doctor-patient communication. Within this field, different prototypes of doctor-patient relationship styles are described according to the amount of patient autonomy and physician's authority (Roter and Hall, 1992).

The traditional 'non-disclosure model' assumes that informing the patient evokes fear and anxiety, the doctor-patient relationship is characterized as a paternalistic one, where the doctor decides what is best for the patient.

The non-disclosure model is an example of the prototype of paternalism which is widely regarded as the most traditional and most common form of doctor-patient relationship. Within this doctorcentred model, the patient adopts a dependent and passive role, while the doctor assumes a dominant role in which he autonomously decides over treatment in the patient's best interest. Also, as far as information giving is concerned, the doctor decides how much and which information is provided to the patient. Within a paternalistic relationship model, the doctor maintains emotional detachment and distance from the patient. Physicians who approve a non-disclosure model also value the importance of keeping hope for the patient who is seriously ill. The empirical base for this model is provided in several studies (Husebo, 1997; Lynch and Burnett, 1997; Surbone, 1997) that have illustrated a positive relationship between 'hope' and quality of life of the patient who is seriously ill.

The full-disclosure model implies giving full information to each patient and stresses the ethical right of each individual on knowing the truth. Several studies support the idea that patients want to be fully informed and have a high need for information (Cassileth et al., 1980; Blanchard et al., 1988; Meredith et al., 1996). For example, a Japanese study (Ido, 1996) stated that $90 \%$ of the patients want to know their diagnosis and prognosis. The full-disclosure model is illustrative of a doctor-patient relationship prototype, which is described as 'consumerism' and is the opposite extreme of paternalism. This model reverses the power relationship and puts the decision-making responsibility under the patient's control. The role of the doctor is defined as a provider of health services and the medical encounter is seen as a marketplace transaction. Regarding information-giving strategies, this approach stresses the necessity of giving the patient full access to his medical chart in order to guide him in his decision making. Several empirical studies (Cassileth et al., 1980; Greenfield et al., 1988; Kaplan et al., 1989) have also reported that patients who are involved in decision-making strategies were significantly more hopeful, and had an overall better medical condition than patients who adopt the traditional passive dependent role.

The individualized disclosure model recognizes that the amount of information disclosed should best be tailored to the information preferences of each patient. Several studies (Cassileth et al., 1980; Steptoe and O'Sullivan, 1986; Miller, 1995; Butow et al., 1996) have indicated that patients differ in information preferences regarding bad news. Several factors account for these differences, including primary tumour site (Arraras et al., 1995), socio-demographic variables, and coping with threatening medical information (Miller, 1995). The individualized disclosure model is an example of the prototype of mutuality, which is a doctor-patient relationship style that presents a moderate alternative between the extremes of paternalism and consumerism. This model puts equal weight on the perspectives of both the patient and the physician, and encourages negotiation in the medical encounter. Thereby, the medical expertise is fully utilized in determining treatment decisions, while 
Valck, C. de, Bensing, J., Bruynooghe, R.

Medical students' attitudes towards breaking bad news: an empirical test of

the World Health Organization model.

Psycho-Oncology: 10, 2001, p. 398-409

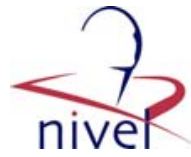

respecting the patient's viewpoint. Regarding information-giving strategies, the mutuality model regards it as an important task of the physician to detect the information preferences of each individual patient, and consequently, to inform the patient according to these preferences.

Overall, according to the WHO brochure, the latter model seems most favourable and assumes that the doctor-patient relationship is based on partnership, resulting in joint decision-making style, and doctor-patient communication is described as good.

Although the WHO framework provides an interesting framework on communication of bad news, it has the limitation that it is a normative model which is based on assumptions rather than being supported by empirical evidence. However, the idea of relating different disclosure models to more global concepts like doctor-patient communication, decision-making strategies and doctor- patient relationship styles is very interesting. Therefore, the first aim of our study is to provide empirical support for the proposed theoretical framework of the WHO model.

In the WHO approach, attitudes towards breaking bad news are not considered as isolated concepts, but are related to more global or general professional attitudes that can change over times and places. The relevance of this approach is shown by the fact that, during the last three decades, a significant change in the attitudes of physicians to the disclosure of bad news can be witnessed. For example, in answer to a questionnaire administered in 1961 in the US, 90\% of the respondents indicated a preference for not telling a cancer patient his diagnosis (Oken, 1961); Novack et al. (1979) replicated this study and found that $97 \%$ of the respondents indicated a preference for telling a cancer patient his diagnosis, showing a complete reversal of attitude. Both Novack and Oken also pointed to the fact that the basis of these attitudes are emotion-laden a priori personal judgements of the physician, rather than the patient's needs, thereby suggesting that attitudes regarding breaking bad news are primarily guided by the personal viewpoint of the doctor instead of patient preferences.

How can this change in attitudes be explained? Razavi et al. (1991) suggest that this change, besides other factors, may be determined by a shift from a predominantly paternalistic and authoritarian kind of physician-patient relationship to a relationship in which they feel equal partners. In this sense, it is suggested that attitudes towards giving information are related to a more global professional attitude regarding doctor-patient relationship style. Further evidence concerning a possible link between more global professional attitudes and attitudes regarding breaking bad news is supported by Fallowfield et al. (1998), who found that oncologists showed positive shifts in attitudes towards the patients' psychosocial need, and appeared more patient-centred after a communication skills training course.

So, a second aim of our study is to explore attitudes regarding bad news against the background of more global professional attitudes regarding medical care. In doing so, the research line concerning global professional attitudes regarding medical care will be applied to provide insight in the possible determinants of attitudes regarding bad news. Within the literature on overall doctor-patient communication (De Monchy, 1992) a distinction is made between cure and care-oriented attitudes, and doctor-centred versus patient-centred attitudes. Owing to the biomedical orientation of medical care, professional attitudes are strongly cure-oriented and less care-oriented; this means, for example, that doctors who hold cure-oriented attitudes focus on the prolongation of life rather than on quality of life issues in the case of a life threatening disease. Doctor-centred versus patient-centred attitudes refer to the power shift model of Byrne and Long (1976) in the communication literature. Doctor-centred attitudes reflect an authoritarian doctor-patient relationship, in which the doctor sets the agenda and decides what is best for the patient regarding treatment. Patient-centred attitudes refer to the implementation of the patient's perspective in medical care, incorporating his preferences regarding decision-making strategies and putting value to the psychological and social aspects of the disease.

Batenburg (1997) investigated the contribution of medical education to the development of professional attitudes in medical school. Based on earlier findings (Rezler, 1974) that a biomedical orientation of the medical curriculum results in a decrease of humaneness or patient-centredness, Batenburg evaluated the effects of attitude aimed communication courses on attitude development. Batenburg found, in contrast to earlier findings, a stability of the attitudes with female students reflecting a slighter humane attitude than male students. These gender differences disappeared later on in medical training, when attitudes became more influenced by speciality preference.

Summarizing, the aim of this study is to explore the attitudes of medical students regarding bad news against the background of the more global professional attitudes regarding medical care. First, we will 
Valck, C. de, Bensing, J., Bruynooghe, R.

Medical students' attitudes towards breaking bad news: an empirical test of

the World Health Organization model.

Psycho-Oncology: 10, 2001, p. 398-409

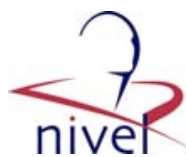

explore the profile of medical students on the more global professional attitudes and the specific attitude regarding bad news delivery. Second, we will investigate the relation between global professional attitudes and specific attitudes regarding bad news disclosure to gain insight in the possible determinants of attitudes regarding bad news delivery. In doing so, we will perform an empirical validation of the WHO model on breaking bad news. We assume that if attitudes regarding bad news delivery correlate with more global professional attitudes, this will have important practical implications for the development of communication skills training.

This leads us to the following research questions:

1. Concerning attitudes towards bad news delivery:

a) What are the attitudes of medical students regarding bad news in terms of the three disclosure models?

b) Do these attitudes change throughout the first 3 years of the curriculum?

c) Do male and female students differ regarding attitudes towards bad news delivery?

d) What are the interrelationships between the different disclosure models of the WHO framework?

2. Concerning the more global professional attitudes regarding medical care:

a) What are the attitudes of medical students concerning the global professional attitudes?

b) Do male and female students differ on these global professional attitudes?

c) What are the interrelationships between global attitudes regarding medical care?

3. In order to provide an empirical test of the WHO model on breaking bad news:

a) How is the relationship between global professional attitudes and attitudes regarding bad news delivery?

b) Is the relationship between global attitudes and attitudes regarding bad news delivery different for male and female students?

4. Concerning a typology of global attitudes and attitudes regarding breaking bad news:

a) Can our sample be divided into subsamples characterized by typical combinations of global and specific attitudes?

b) Are these subsamples gender-related?

\section{METHOD}

\section{Sample}

The study was carried out at the Faculty of Medicine of the Limburgs University Centre in Diepenbeek, Belgium.

Data regarding attitudes towards bad news delivery were collected in a longitudinal design. The Attitudes towards Breaking Bad News Questionnaire (see below) was completed by 85 first year medical students in 1996, 62 second year medical students in 1997, and 88 third year medical students in 1998. Of these respondents, a cohort of 53 students provided longitudinal data regarding attitudes towards bad news delivery, of which 22 were male students and 31 were female students.

Confidentiality was guaranteed by providing an individual code to each individual student in order to link the data sampled over the 3 years. Subjects were tested in classes as part of their compulsory curriculum, excluding self-selection.

Data regarding global professional attitudes of medical care were only collected in the third year sample $(n=88)$, as we were not interested in gaining longitudinal data regarding the global attitudes as specified in our research questions. Of this third year sample, 42 were male and 46 were female subjects.

\section{Questionnaires}

A literature search was performed in order to find reliable and valid measures of attitudes regarding breaking bad news. However, the available questionnaires (Blanchard et al., 1981; Mystakidou et al., 1996; Rodriguez-Marin et al., 1996) proved to be inappropriate to perform an empirical test of the WHO model. Consequently, we developed the Attitudes towards Breaking Bad News Questionnaire for this study as a measure of attitudes regarding disclosure of bad news. A nine-item questionnaire was constructed based on statements referring to the underlying assumptions of the three disclosure 
Valck, C. de, Bensing, J., Bruynooghe, R.

Medical students' attitudes towards breaking bad news: an empirical test of

the World Health Organization model.

Psycho-Oncology: 10, 2001, p. 398-409

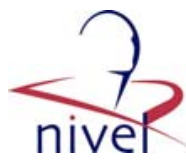

models as formulated by Donovan in the behavioural science learning module on 'communicating bad news' (Donovan, 1993).

In the first version of this scale, each disclosure model was represented by three items, scored on a Likert four-point scale. Subjects are instructed to indicate degree of agreement.

Sample item: non-disclosure model: Patients do not want to hear bad news about themselves.

Sample item: full-disclosure model: Patient has right to full information about self and doctor has obligation to give it.

Sample item: individualized disclosure: Patients are different in their information preferences: some want to hear bad news about themselves, others don't want to hear bad news.

A factor analysis (principal component analysis with varimax rotation) performed on the nine-item version of the Attitudes towards Breaking Bad News Questionnaire failed to represent the three disclosure models. After eliminating three items that lowered the internal consistency of the scales a second factor analysis was performed on the six-item version of the Attitudes towards Breaking Bad News Questionnaire. Inspection of the items revealed that the three items that were eliminated conceptually referred to attitudes regarding decision-making strategies rather than bad news delivery, in a strict sense legitimizing elimination of these items from the Attitudes towards Breaking Bad News Questionnaire. Table 2 presents the results of a forced three-factor solution which can be interpreted as follows.

\section{[ TABLE 2 ]}

The first factor reflects the full-disclosure model, the second factor reflects the non-disclosure model, and the third factor reflects the individualized disclosure model. The reliability of these three scales of two items each measured by Cronbach's alpha ranges from 0.48 to 0.57 . A value of 0.50 has been mentioned in the literature as a sufficient criterium for reliability when comparing final scale scores on group level (Stewart, 1990). The first factor has an eigenvalue of 1.9 and explains $31.9 \%$ of the variance, the second factor has an eigenvalue of 1.3 and explains $21.9 \%$ of the variance, the third factor has an eigenvalue of 1 and explains $16 \%$ of the variance. Together, the three factors explain $70 \%$ of the total variance, which is very high for a six-item questionnaire. On the basis of this factor analysis, we may conclude that the six-item version of the Attitudes towards Breaking Bad News Questionnaire provides a valid and reliable instrument to measure attitudes regarding disclosure of bad news, which theoretically fits the three disclosure model of the WHO. A separate score can be calculated for each disclosure model (range 2-8), with a higher score indicating more agreement.

For the assessment of global professional attitudes, existing questionnaires were employed in order to compare the collected data in view of the findings of earlier studies. The Ideal Physician Questionnaire (IP) (Batenburg, 1997) was used to measure cure versus care attitudes regarding the medical profession. This Likert scale consists of 18 bipolar items describing traits of the ideal physician, for example, democratic as opposed to hierarchical, committed versus distant, person versus diseasecentred. Agreement is indicated on a seven-point scale of the Likert type. The reliability of this instrument, measured by Cronbach's alpha is 0.63 , which is satisfactory. Total scores are transformed into final mean scale scores (range 1-7). Scores between 3.5 and 4.5 are interpreted as neutral, scores above 4.5 are interpreted as care-oriented, scores below 3.5 are interpreted as cure-oriented.

The Dutch version (Batenburg, 1997) of Doctor- Patient Scale (DP) by De Monchy et al. (1988) was employed as a measuring instrument for doctor- vs patient-centredness. This questionnaire consists of 48 statements regarding attitudes towards patients and the doctor-patient relationship. Subjects are instructed to indicate agreement or disagreement with these statements on a fivepoint scale of the Likert type. Reliability of the Dutch version of this scale, measured by Cronbach's alpha, is 0.78 , which is sufficient. Statement total scores are calculated for the 48 items, and then transformed into final mean scale scores (range 1-5). Final scores of 3.5 or above are interpreted as humane, final scores of 2.5 or below are interpreted as technological. Scores between 2.5 and 3.5 are interpreted as neutral. 
Valck, C. de, Bensing, J., Bruynooghe, R.

Medical students' attitudes towards breaking bad news: an empirical test of

the World Health Organization model.

Psycho-Oncology: 10, 2001, p. 398-409

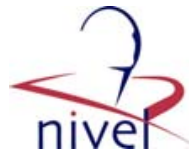

Sample item: Doctor-Patient Scale: Listening to patients is more efficient than talking to them.

Finally, the Social Context Scale (SO) (Batenburg, 1997) was employed to measure the psychosocial orientation regarding disease. This questionnaire consists of 10 statements on the importance of somatic versus psychosocial factors in health and illness. The scale is unidimensional, with one pole representing a biomedically-oriented and the other pole a psychosocially-oriented attitude. Subjects are instructed to indicate agreement on a five point Likert scale. Reliability of this scale, measured by Cronbach's alpha, is 0.64, which is sufficient. Statement total scores are calculated for the ten items, and then transformed into mean scale scores (range 1-5); final scores of 3.5 or above are interpreted as humane, final scores of 2.5 or below are interpreted as technological. Scores between 2.5 and 3.5 are interpreted as neutral.

Sample item: Social Context Scale I am more interested in somatic aspects than in psychosocial aspects of disease.

\section{Statistical analysis}

Data were analysed using the SPSS 8.0 for Windows Package.

\section{RESULTS}

\section{Attitudes regarding disclosure of bad news}

Table 3(a) presents the longitudinal results on the Attitudes towards Breaking Bad News Questionnaire. Mean scale scores are presented for the non-disclosure (Nondis), full-disclosure (Fuldis) and the individualized disclosure (Inddis) model. Scores range between 2 and 8, higher scores indicate more agreement. Differences at different point in time (first year, second, third year) and between mean scale scores have been analysed by repeated measures analysis of variance. $p$ Values of 0.05 and lower were considered significant. Table $3(\mathrm{~b})$ presents the results of the repeated measures analysis of variance.

\section{[ TABLE 3 ]}

\section{Main effect of disclosure model.}

Comparison of the mean scores for the three disclosure scales shows greater agreement with an individualized disclosure model than with a full-disclosure model or a non-disclosure model. The preference for an individualized disclosure model is apparent in all three classes $(F=176.821, \mathrm{df}=2$, $p=0.000$ ).

There was no significant effect of time $(F=0.765, \mathrm{df}=2, p=0.471)$.

\section{Interaction effect of time and model.}

Comparison of the mean scores between first year, second year and third year students shows a significant change in attitudes on the three scales of the Attitudes regarding Breaking Bad News Questionnaire $(F=3.725, \mathrm{df}=9, p=0.01)$. The attitudes of third year students change in the direction of more agreement with a non-disclosure model compared with their scores in the first and second year of medical education. The attitudes of third year students also show a significant change in the direction of less agreement, with a full disclosure, and with an individualized disclosure model as compared with their scores in the first and the second year of their medical education.

Table 4 presents the results of the comparison between female and male students on the Attitudes regarding Breaking Bad News Questionnaire calculated by univariate analysis of variance. There appear to be no significant differences between male and female students regarding their attitudes towards breaking bad news, except for their attitudes concerning full-disclosure in the second year. In the second year, female students show more agreement with a full-disclosure model than male students $(p=0.023)$, but this difference disappears in the third year of medical education. 
Valck, C. de, Bensing, J., Bruynooghe, R.

Medical students' attitudes towards breaking bad news: an empirical test of

the World Health Organization model.

Psycho-Oncology: 10, 2001, p. 398-409

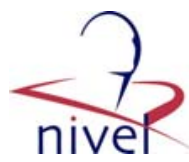

\section{[ TABLE 4 ]}

Interrelationships between non-disclosure score, full-disclosure score and the individualized disclosure score are analysed by Pearson correlation coefficients, and are presented separately for male and female students in order to explore possible gender differences.

For the male students, there are no significant intercorrelations for the attitudes regarding breaking bad news. Regarding the attitudes concerning the disclosure of bad news of female students, there is a negative relationship between the nondisclosure score and the full-disclosure score $(r=-0.397, p=$ $0.006)$. The individualized disclosure score is positively correlated with the non-disclosure score $(r=$ $0.363, p=0.013)$ and negatively correlated with the full-disclosure score $(r=-0.440, p=0.002)$.

\section{Global professional attitudes regarding medical care}

Table 5 presents the results of the third year students on the IP, the DP and the SO. In line with our second research question, mean total scores of male and female students are compared by Student's $t$ test.

\section{[ TABLE 5 ]}

There is an influence of gender on two of the three scales. Female students score significantly higher than male students on the DP $(p=0.002)$ and on the SO $(p=0.04)$. There are no significant gender differences on the IP.

The mean scores for the three scales all fall within the 'neutral' range.

The IP scores, measuring cure versus care orientation, range from 3.72 to 4.12 , and reflect a 'neutral' orientation. The DP score, measuring doctor- vs patient-centredness, ranges from 3.30 to 3.46, and also reflects a 'neutral' attitude. The SO score, measuring psychosocial orientation, ranges from 3.21 to 3.37 , and is also to be interpreted as 'neutral'.

Interrelationships between the SO score, the DP score and the IP score are analysed by Pearson correlation coefficients separately for male and female students in order to explore possible gender differences. For male students, there is a significant positive relationship between the DP score and SO score $(r=0.507 ; p=0.001)$, meaning that doctor-patient-centredness and psychosocial orientation are interrelated. There is also a significant positive relationship between the IP score and SO score $(r=$ $0.393 ; p=0.012$ ) meaning that cure versus care orientation and psychosocial orientation are interrelated. The IP score is also positively correlated with the DP score $(r=0.564 ; p=0.000)$, meaning that cure versus care orientation and doctor-patient-centredness are interrelated. Regarding the interrelationships between the global professional attitudes regarding medical care, the data of female students are comparable with the male students. The DP score is positively correlated to the SO score $(r=0.617 ; p=0.000)$ and the IP score $(r=0.400 ; p=0.009)$, meaning that doctor-patientcentredness and cure versus care orientation and psychosocial orientation are strongly interrelated. The IP score is also positively correlated to the SO score $(r=331, p=0.25)$, meaning that there is a positive relationship between cure vs care orientation and psychosocial orientation.

Together, all the global professional attitudes regarding medical care appear to intercorrelate.

\section{Relationship between global professional attitudes and attitudes regarding breaking bad news}

The interrelationships between the IP score, the DP score, the SO score and the non-disclosure, the full-disclosure and individualized disclosure scores are analysed by Pearson correlation coefficients, and are presented separately for male and female students in order to explore possible gender differences.

For female students, there is only one significant positive relationship. The individualized disclosure score is positively correlated with the IP score $(r=0.381, p=0.009)$, meaning that female students who agree with an individualized disclosure model are also more care-oriented. For the male respondents, there is one significant relationship between a global professional attitude and attitudes regarding breaking bad news: there appears to be a negative relationship between the full-disclosure score and the SO score $(r=-0.511, p=0.001)$, meaning that male subjects who agree with a fulldisclosure model are less psychosocially oriented. 
Valck, C. de, Bensing, J., Bruynooghe, R.

Medical students' attitudes towards breaking bad news: an empirical test of

the World Health Organization model.

Psycho-Oncology: 10, 2001, p. 398-409

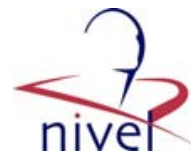

\section{Cluster analysis combining global professional attitudes and attitudes regarding the disclosure of bad news.}

A $k$ means cluster analysis was performed in order to explore if the sample can be divided into subsamples characterized by a specific combination of global attitudes regarding medical care and attitudes regarding the disclosure of bad news. Table 6 presents the results of the cluster analysis.

\section{[ TABLE 6 ]}

The sample of 81 subjects of third year medical students can be divided into three clusters as follows. Cluster 1 contains 27 subjects of which, 12 male and 15 female subjects. Cluster 1 holds technical global professional attitudes as indicated by their negative Z-scores on the SO scale, the DP scale and the IP scale. Regarding breaking, bad news subjects in cluster 1 disagree with a non and an individualized disclosure model but agree with a full-disclosure model.

Cluster 2 contains 19 subjects, of which six were male subjects and 13 were female subjects. Cluster 2 holds humane global professional attitudes as indicated by their positive Z-scores on the SO scale, the DP scale and the IP scale. Regarding breaking bad news subjects in cluster 2 agree with a fulldisclosure model, as well as with an individualized disclosure model.

Cluster 3 contains the majority of the total sample, and contains 35 subjects, of which 21 were male subjects, and 14 were female subjects. Regarding global professional attitudes, cluster 3 is neutral for doctor-patient-centredness and cure-care orientation, but humane on psychosocial orientation.

Regarding breaking bad news, cluster 3 disagrees with a full-disclosure model, and is rather neutral towards individualized and non-disclosure.

In cluster 1, the proportion of male and female subjects is comparable; in cluster 2, the proportion of female subjects is higher; in cluster 3 , the proportion of male subjects is higher.

\section{CONCLUSION AND DISCUSSION}

In this study, we wished to gain further insight in the attitudes of medical students regarding the disclosure of bad news. We empirically explored some aspects of the theoretical framework of the WHO, which relates more global attitudes regarding medical care to different models of disclosure of bad news.

Regarding our first research question, we may conclude the following. First, it proved to be possible to develop a reliable and valid instrument to measure attitudes regarding disclosure of bad news. The Attitudes towards Breaking Bad News Questionnaire is a short six-item questionnaire, consisting of three scales, respectively, measuring attitudes regarding non-disclosure, attitudes regarding fulldisclosure and attitudes regarding individualized disclosure. These scales represent an operationalization of the WHO framework concerning bad news disclosure models. In our longitudinal sample of medical students, we found a significant preference for an individualized disclosure model. This is consistent with the literature regarding the evolution of attitudes towards breaking bad news over time, describing a shift towards more patient-centred individualized disclosure in the last decennia (Novack et al., 1979; Razavi et al., 1991). These results are also consistent with the evolution of the traditional model of a paternalistic doctor-patient relationship to a more egalitarian model of mutuality in the medical encounter (Roter and Hall, 1992).

The results also show a significant change in the respondents' attitudes regarding breaking bad news over the first 3 years of their curriculum. There is significantly more agreement with a nondisclosure model in the third year in comparison with the second and first year of the curriculum, parallel to this shift is a decline in agreement with a full-disclosure and an individualized disclosure model. These findings suggest that the decline in humaneness, as described in the literature (Powell et al., 1987; Wolf et al., 1989) as a consequence of the biomedically oriented curricula in medical education, is also reflected in the attitudes regarding breaking bad news. Humaneness can be understood as a mode of behaviour by which more room is given to the patient's view and refers to the affective components of the consultation (Bensing, 1991). Rosenthal and Ogden (1998) showed that medical students' beliefs varied with stage of training, with a high score for psychosocial orientation in year 1 and a decline in the third year, followed by a renewed interest in psychosocial matters in year 5. Makoul (1998) also 
Valck, C. de, Bensing, J., Bruynooghe, R.

Medical students' attitudes towards breaking bad news: an empirical test of

the World Health Organization model.

Psycho-Oncology: 10, 2001, p. 398-409

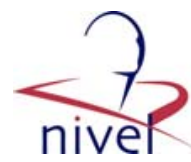

found a clear evolution in medical students' views and educational needs on breaking bad news with first year students focusing more on interpersonal topics, such as not being sensitive for the patient's needs and residents at the end of medicine internship focusing more on knowledge issues, such as fear of not being able to answer a question. In our data, however, the change in attitudes regarding bad news towards more agreement with non-disclosure is not so strong that it becomes to be preferred over the individualized disclosure model in the third year. The relative preference for the individualized disclosure model persists, despite the significant changes in attitudes over the first 3 years.

Further, there appear to be no remarkable gender differences regarding attitudes towards breaking bad news. This is an interesting fact, which contrasts with studies describing gender differences regarding the more global attitudes in medical care (Batenburg, 1997; Hall and Roter, 1998) which report more humane attitudes in female subjects.

Regarding the interrelationship between the different disclosure models, the results show a negative relationship between attitudes regarding non-disclosure and attitudes regarding full-disclosure for the female respondents, but this is not replicated in the male sample. The individualized disclosure model is not significantly correlated to either the full- or the non-disclosure model for the male subjects, while for the female subjects, individualized disclosure is positively related with non-disclosure, and negatively with full-disclosure. As discussed earlier, the concept of an individualized disclosure model refers to a mutuality model in the doctor-patient relationship, while non-disclosure is associated with paternalism, and full-disclosure with consumerism. According to Roter and Hall (1992), paternalism and consumerism are extremes, and this appears to be reflected in the negative correlation between nondisclosure and full-disclosure in our female sample.

Regarding our second research question concerning the global professional attitudes, our results were compared with data of a third year Dutch sample gathered in a study by Batenburg (1997). Our results partially replicate the gender differences reported by Batenburg (1997) describing more humane attitudes in female students. In our sample, female students of the third year are more patient-centred and more psychosocially oriented than male students, which is consistent with Bateburg's findings. For cure versus care orientation, as measured by the Ideal Physician Scale, there are no significant gender differences in our sample, while in Batenburg's study, female subjects are more care-oriented than male subjects. However, these 'differences' have to be interpreted with caution because all the scores range in the neutral part of the Likert scale, suggesting that the Belgian and the Dutch sample hold no extreme, but rather 'neutral' global attitudes regarding medical care. Further, there is a strong positive interrelationship between global professional attitudes which is comparable for female and male students. This means that doctor- patient-centredness and cure versus care orientation and psychosocial orientation are strongly interrelated, and suggesting that they refer to a rather 'fuzzy' concept that should be clarified by further research.

Concerning our third research question, regarding the relation between bad news disclosure and more global attitudes, as suggested by the WHO framework, we may conclude the following. Overall, the intercorrelations between the more global attitudes and the attitudes regarding bad news were poor. We found only one significant correlation for the nine correlations examined, which was different for male and female students. Attitudes regarding full-disclosure are negatively correlated to psychosocial orientation for male students but not for female students; for female students, there is a significant positive relationship between attitudes regarding individualized disclosure and their cure versus care orientation.

Summarizing, we may conclude that our results only partially empirically validate the WHO framework. On the basis of factor analysis, it proved to be possible to operationalize the three proposed disclosure models in the Attitudes towards breaking Bad News Questionnaire. Regarding the relation between these disclosure models and more global professional attitudes our findings do not support the proposed framework.

Further, our data suggest that attitudes regarding breaking bad news are related to different global attitudes for male and female subjects, but this is to be replicated by further research investigating the relationship between medical communication and gender as recently suggested by Hall and Roter (1998). Roter and Hall (1998) report that female physicians show a greater affinity for collaborative models of patient-physician relationship than do their male partners. 
Valck, C. de, Bensing, J., Bruynooghe, R.

Medical students' attitudes towards breaking bad news: an empirical test of

the World Health Organization model.

Psycho-Oncology: 10, 2001, p. 398-409

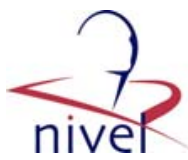

Finally, a cluster analysis was performed to explore if the respondents could be distinguished in subsamples representing different 'disclosure clusters' combining global and disclosure attitudes. The results of the cluster analysis suggest three types of combinations of attitudes. First, a group of respondents favouring full-disclosure with technological global attitudes; second, a group of subjects favouring full-disclosure with humane global attitudes, and finally, a group of subjects not favouring full-disclosure with neutral attitudes on cure versus care and doctor versus patient-centredness, but rather, psychosocially oriented. This is a very interesting finding because it suggests that subjects favouring a full-disclosure model may differ regarding their global professional attitudes. The first cluster seems to favour full-disclosure in a biomedically oriented and emotionally detached way, while the second cluster favours full-disclosure with a caring, psychosocially- oriented attitude. Again, it is worth noting that, in the second 'caring' cluster, we find relatively more female respondents. The majority of the sample in the third cluster is against full-disclosure and neutral toward non- or individualized disclosure, but psychosocially-oriented. It appears as if they don't have a preference for one or another disclosure model, as if they 'don't know'.

On the basis of the results of the cluster analysis, we may conclude that our subjects can be divided into subsamples of specific combinations of attitudes, and this reveals that a preference for a specific disclosure model can 'cover' different global professional attitudes. These results may be relevant in order to explain differences in attitudes regarding bad news, which might be related to different behaviours in breaking bad news. In our further research line, concerning the determinants of communicative behaviour in breaking bad news, we will examine whether subjects with different attitudes also behave differently when breaking bad news.

\section{TABLES}

Table 1. WHO framework describing comparison of disclosure models (Donovan, 1993)

\begin{tabular}{llll}
\hline Model & $\begin{array}{l}\text { Doctor-patient } \\
\text { relationship }\end{array}$ & $\begin{array}{l}\text { Management } \\
\text { decision-making style }\end{array}$ & $\begin{array}{l}\text { Doctor-patient } \\
\text { communication }\end{array}$ \\
\hline $\begin{array}{l}\text { Non-disclosure } \\
\text { Full-disclosure }\end{array}$ & Paternalistic & Physician only & Poor \\
Individualized disclosure & Paternalistic & Patient only & Fair \\
\hline
\end{tabular}

Table 2. Factor analysis on six-item version of the Attitudes towards Breaking Bad News Questionnaire

\begin{tabular}{|c|c|c|c|c|c|}
\hline Factor 1: full-disclosure ${ }^{a}$ & & Factor 2: non-disclosure ${ }^{\mathrm{b}}$ & & Factor 3: individualized disclosu & $\mathrm{re}^{\mathrm{c}}$ \\
\hline $\begin{array}{l}\text { * Patients have right to full in- } \\
\text { formation about self and } \\
\text { doctor has obligation to give } \\
\text { it }\end{array}$ & 0.81 & $\begin{array}{l}\text { * Patients do not want to hear } \\
\text { bad news about themselves }\end{array}$ & 0.860 & $\begin{array}{l}\text { * Patients are different in their } \\
\text { information preferences }\end{array}$ & 0.658 \\
\hline $\begin{array}{l}\text { * All patients want to know } \\
\text { bad news about themselves }\end{array}$ & 0.811 & $\begin{array}{l}\text { * Patients need to be protected } \\
\text { from bad news }\end{array}$ & 0.732 & $\begin{array}{l}\text { * It takes time to absorb and } \\
\text { adjust to bad news }\end{array}$ & 0.888 \\
\hline
\end{tabular}

alpha $=0.57 ;$ variance $=31.9 \%$; eigenvalue $=1.9$.

${ }^{\mathrm{b}}$ Alpha $=0.48 ;$ variance $=21.9 \%$; eigenvalue $=1.3$

${ }^{\mathrm{c}}$ Alpha $=0.40$; variance $=16.7 \%$; eigenvalue $=1.0$

Total variance explained $=70.6 \%$. 
Valck, C. de, Bensing, J., Bruynooghe, R.

Medical students' attitudes towards breaking bad news: an empirical test of

the World Health Organization model.

Psycho-Oncology: 10, 2001, p. 398-409

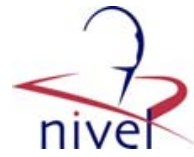

Table 3. (a) Mean scores on Attitudes towards Breaking Bad News Questionnaire ( $n=52)$; (b) repeated measures analysis of variance for effect of time and model

\begin{tabular}{|c|c|c|c|c|c|c|}
\hline \multirow[b]{2}{*}{ (a) } & \multicolumn{2}{|c|}{ Non-disclosure } & \multicolumn{2}{|c|}{ Full-disclosure } & \multicolumn{2}{|c|}{$\begin{array}{l}\text { Individualized } \\
\text { disclosure }\end{array}$} \\
\hline & $X$ & S.D. & $X$ & S.D. & $X$ & S.D \\
\hline 1st year-T1 & 3.88 & 1.17 & 7.15 & 0.82 & 7.63 & 2.83 \\
\hline 2nd year-T2 & 4.02 & 1.21 & 6.92 & 0.81 & 7.42 & 0.75 \\
\hline 3 rd year- $\mathrm{T} 3$ & 4.15 & 1.16 & 6.64 & 0.92 & 7.37 & 0.71 \\
\hline (b) & $F$ & $p$ & & & & \\
\hline Main effect of time & 0.765 & 0.471 & & & & \\
\hline Main effect of model & 176.821 & 0.000 & & & & \\
\hline Interaction effect time $\times$ model & 3.725 & 0.01 & & & & \\
\hline
\end{tabular}

Range (2-8).

* Higher scores indicate more agreement.

Table 4. Differences in mean scores on Attitudes Towards Breaking Bad News Questionnaire between male $(n=22)$ and female $(n=31)$ first year, second year and third year medical students

\begin{tabular}{|c|c|c|c|c|c|c|c|c|c|c|c|c|c|c|c|}
\hline & \multicolumn{5}{|c|}{ Non-disclosure } & \multicolumn{5}{|c|}{ Full-disclosure } & \multicolumn{5}{|c|}{ Individualized disclosure } \\
\hline & \multicolumn{2}{|c|}{ Male } & \multicolumn{2}{|c|}{ Female } & \multirow[t]{2}{*}{$p$} & \multicolumn{2}{|c|}{ Male } & \multicolumn{2}{|c|}{ Female } & \multirow[t]{2}{*}{$p$} & \multicolumn{2}{|c|}{ Male } & \multicolumn{2}{|c|}{ Female } & \multirow[t]{2}{*}{$p$} \\
\hline & $X$ & S.D. & $X$ & S.D. & & $X$ & S.D. & $X$ & S.D. & & $X$ & S.D. & $X$ & S.D. & \\
\hline 1st year & 3.86 & 1.08 & 3.90 & 1.22 & 0.904 & 7.0 & 0.75 & 7.26 & 0.86 & 0.254 & 7.22 & 0.68 & 7.93 & 3.67 & 0.379 \\
\hline 2nd year & 4.33 & 1.27 & 3.80 & 1.13 & 0.125 & 6.61 & 0.74 & 7.13 & 0.78 & 0.023 & 7.47 & 0.74 & 7.37 & 0.77 & 0.660 \\
\hline 3 nd year & 4.18 & 1.13 & 4.12 & 1.20 & 0.873 & 6.4 & 1.09 & 6.8 & 0.74 & 0.123 & 7.31 & 0.77 & 7.41 & 0.67 & 0.616 \\
\hline
\end{tabular}

Table 5. Mean score of third-year male $(n=42)$ and female $(n=46)$ students on the IP, the DP and the SO scores

\begin{tabular}{lllllllll}
\hline & \multicolumn{2}{l}{ Male } & \multicolumn{3}{l}{ Female } & & $\alpha$ \\
\cline { 2 - 3 } & $X$ & S.D. & & $X$ & \multicolumn{2}{c}{ S.D. } & & \\
\hline IP score & 4.03 & 0.41 & & 4.17 & 0.39 & 0.12 & 0.63 \\
DP score & 3.30 & 0.21 & & 3.46 & 0.24 & 0.002 & 0.78 \\
SO score & 3.21 & 0.36 & & 3.37 & 0.36 & 0.04 & 0.64 \\
\hline
\end{tabular}

Differences were tested by two sided $t$-test.

Table 6. Cluster analysis on third year medical students $(n=81)$ combining global professional attitudes and attitudes regarding disclosure of bad news

\begin{tabular}{|c|c|c|c|}
\hline & $\begin{array}{l}\text { Cluster } 1 \\
n=27\end{array}$ & $\begin{array}{l}\text { Cluster } 2 \\
n=19\end{array}$ & $\begin{array}{l}\text { Cluster } 3 \\
n=35\end{array}$ \\
\hline & $\begin{array}{l}M=12 \\
F=15\end{array}$ & $\begin{array}{l}M=6, \\
F=13\end{array}$ & $\begin{array}{l}M=21 \\
F=14\end{array}$ \\
\hline SO score-psychosocial orientation & -0.869 & 0.387 & 0.482 \\
\hline DP score-doctor-patient-centredness & -0.730 & 0.974 & 0.058 \\
\hline IP score-cure-care orientation & -0.740 & 0.865 & 0.045 \\
\hline ND score-non-disclosure & -0.286 & 0.186 & 0.058 \\
\hline FD score-full-disclosure & 0.463 & 0.733 & -0.767 \\
\hline ID score-individualized disclosure & -0.598 & 0.370 & 0.22 \\
\hline
\end{tabular}

$\mathrm{M}=$ male, F-female 
Valck, C. de, Bensing, J., Bruynooghe, R.

Medical students' attitudes towards breaking bad news: an empirical test of

the World Health Organization model.

Psycho-Oncology: 10, 2001, p. 398-409

\section{REFERENCES}

1. Arraras JI, Illarramendi JJ, Valerdi JJ, Wright SJ. 1995. Truth-telling to the patient in advanced cancer: family information filtering and prospects for change. Psycho-Oncology 4: 191-196.

2. Batenburg V. 1997. Medical Students' Attitudes: Attitude Development in a Medical School. Published Manuscript. Elinkwijk BV: Utrecht.

3. Bensing J. 1991. Doctor-Patient Communication and the Quality of Care. Published Manuscript. Nivel: Utrecht.

4. Blanchard CG, Labrecque MS, Ruckdeschel JC, Blanchard EB. 1988. Information and decision-making preferences of hospitalised adult cancer patients. Soc Sci Med 27(11): 11391145.

5. Blanchard CG, Ruckdeschel JC, Cohen RE, Shaw E, Mcsharry J, Horton J. 1981. Attitudes toward cancer: the impact of a comprehensive oncology course on second year medical students. Cancer 47(11): 2756-2761.

6. Buckman R. 1988. I Don't Know What to Say. Macmillan: London.

7. Burton MV, Parker RW. 1997. Psychological aspects of cancer surgery: surgeons' attitudes and opinions. Psycho-Oncology 6: 47-64.

8. Butow PN, Kazemi JN, Beeney LJ, Griffin AM, Dunn SM, Tattersall MHN. 1996. When the diagnosis is cancer: patient communication experiences and preferences. Cancer 77(12): 2630-2637.

9. Byrne PS, Long BEL. 1976. Doctors Talking to Patients. A Study of the Verbal Behaviour of General Practitioners Consulting in their Surgeries. HSMO, RCGP: London.

10. Cassileth BR, Zupkis RV, Sutton-Smith K, March V. 1980. Information and participation preferences among adult cancer patients. Ann Intern Med 92: 832-836.

11. Donovan K. 1993. Breaking bad news. In Communicating Bad News. Behavioural Science Learning Modules. Division of Mental Health, World Health Organisation: Geneva; 3-14.

12. De Monchy C, Richardson R, Brown RA, Horden RM. 1988. Measuring attitudes of doctors: the doctor- patient (DP) rating. Med Ed 22: 231-239.

13. De Monchy C. 1992. Professional attitudes of doctors and medical teaching. Med Teacher 14(4): 327-331.

14. Fallowfield L, Ford S, Lewis S. 1995. No news is not good news: information preferences of patients with cancer. Psycho-Oncology 4: 197-202.

15. Fallowfield L, Lipkin M, Hall A. 1998. Teaching senior oncologists communication skills: results from phase I of a comprehensive longitudinal program in the United Kingdom. J Clin Oncol 16(5): 1961-1968.

16. Greenfield S, Kaplan SH, Ware Jr JE, Yano EM, Frank HJ. 1988. Patients' participation in medical care: effects on blood sugar control and quality of life in diabetes. J Gen Intern Med 3: 448-457.

17. Hall JA, Roter DL. 1998. Medical communication and gender: a summary of research. J GenSpec Med 1: 39-42.

18. Husebo S. 1997. Communication, autonomy and hope: how can we treat seriously ill patients with respect? In Communication with the Cancer Patient: Information and Truth. Annals of the New York Academy of Sciences, vol. 809, Surbone A, Zwitter M (eds). New York Academy of Sciences: New York; 440-459.

19. Ido K. 1996. Gastroenterologists disagree on telling whole truth. Lancet 348: 987.

20. Kaplan SH, Greenfield S, Ware JE. 1989. Assessing the effects of physician-patient interactions on the outcomes of chronic disease. Med Care 27(Supplement): S110-S127.

21. Lynch A, Burnett C. 1997. Ethical dimensions and communication issues in nursing patients with advanced metastatic cancer. In Communication with the Cancer Patient: Infformation and Truth. Annals of the New York Academy of Sciences, vol. 809, Surbone A, Zwitter M (eds). New York Academy of Sciences: New York; 172-178.

22. Maguire $P$, Booth $K$, Elliott $C \&$, Jones $B$. 1996. Helping health professionals involved in cancer care acquire key interviewing skills—-the impact of workshops. Eur J Cancer 32(9): 14981499.

23. Makoul G. 1998. Medical student and resident perspectives on delivering bad news. Acad Med 73(10, Supplement): S35-S37.

24. Meredith C, Symonds P, Webster L, Lamont D, Pyper E, Gillis C, Fallowfield I. 1996. Information needs of cancer patients in west Scotland: cross sectional survey of patientts views. Br Med J 313: 724-726.

25. Miller SM. 1995. Monitoring versus blunting styles of coping with cancer influence the information patients want and need about their disease. Cancer 76(2): 167-177. 
Valck, C. de, Bensing, J., Bruynooghe, R.

Medical students' attitudes towards breaking bad news: an empirical test of

the World Health Organization model.

Psycho-Oncology: 10, 2001, p. 398-409

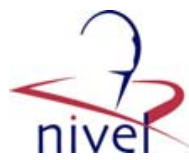

26. Mystakidou K, Liossi C, Vlachos L, Papadimitriou J. 1996. Disclosure of diagnostic information to cancer patients in Greece. Pall Med 10: 195-200.

27. Novack DH, Plumer R, Smith RL, Ochitill H, Morrow GR, Bennett JM. 1979. Changes in physicians' attitudes toward telling the cancer patient. JAMA 241(9): 897-900.

28. Oken D. 1961. What to tell cancer patients: a study of edical attitudes. JAMA 175: 1120-1128.

29. Powell A, Boakes J, Slater P. 1987. What motivates medical students: how they see themselves and their profession. Med Ed 21: 176-182.

30. Razavi D, Delvaux N, Farvacques C, Robaye E. 1991. Brief psychological training for health care professionals dealing with cancer patients: a one year assessment. Gen Hosp Psychiatry 13: 253-260.

31. Rezler AG. 1974. Attitude changes during medical school: a review of the literature. J Med Ed 49: 1023-1030.

32. Rodriguez-Marin J, Lopez-Roig SL, Pastor MA. 1996. Doctor's decision-making on giving information to cancer patients. Psychol Health 11(6): 839-844.

33. Rosenthal J, Ogden J. 1998. Changes in medical education: the beliefs of medical students. Med Ed 32: 127-132.

34. Roter DL, Hall J. 1992. Doctors Talking with Patients. Patients Talking with Doctors. Auburn House: Westport, CT.

35. Roter DL, Hall JA. 1998. Why physician gender matters in shaping the physician patient relationship. J Wom Health 7(9): 1093-1097.

36. Steptoe A, O'Sullivan J. 1986. Monitoring and blunting styles in women prior to surgery. $\mathrm{Br} \mathrm{J}$ Clin Psychol 25: 143-144.

37. Surbone A. 1997. Truth-telling, risk and hope. In Communication with the Cancer PatientInformation and Truth. Annals of the New York Academy of Sciences, vol. 809, Surbone A, Zwitter M (eds). New York Academy of Sciences: New York; 72-79.

38. Stewart AL. 1990. Psychometric considerations in functional status instruments. In Functional Status Measurement in Primary Care. WONCA Classification Committee, Springer-Verlag: New York; 3-26.

39. Wolf TM, Balson PM, Faucett JM, Randall HM. 1989. A retrospective study of attitude change during medical education. Med Ed 23: 19-23. 